\section{Revista Chilena de Pediatría}

www.revistachilenadepediatria.cl

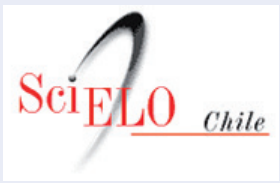

www.scielo.cl

Rev Chil Pediatr. 2020;91(3):467-468

DOI: 10.32641/rchped.v91i3.2402

CARTA AL EDITOR

\section{Una nota de alerta toxicológica en tiempos de pandemia}

\section{A note of toxicological alert in pandemic times}

\section{Sr. Editor}

Las complicaciones de la enfermedad denominada COVID-19 aunque escasas, son progresivamente más conocidas para la población infantil, sin embargo, en el presente contexto de control sanitario pueden aparecer otros riesgos para su salud no tan evidentes. La permanencia obligada de los niños en cuarentena y la gran disponibilidad de alcohol intradomiciliario como producto de limpieza e higiene personal en sus muy diversas formas de presentación (gel, spray, líquido) ${ }^{1}$, esto último motivado como una recomendación para su uso cuando no fuese posible el lavado de manos ${ }^{2}$, desde instituciones sanitarias, medios de comunicación y publicitarios han generado la posibilidad de intoxicarse por etanol mediante la manipulación de estos productos potencialmente riesgosos para niños pequeños.

Dado un reciente caso de una niña de cuatro años quién fue tratada en nuestra unidad por intoxicación etílica (4 g/kg), luego de lamer e ingerir alcohol gel, nos pareció importante hacer un llamado de alerta y recordar concisamente algunos aspectos clínicos y terapéuticos sobre esta intoxicación potencialmente letal.

El alcohol gel está constituido por alcohol etílico, isopropílico o propílico al 70\%, agua, glicerina, agentes humectantes y suavizantes. El alcohol se absorbe en estómago (70\%) y duodeno (25\%). Los niveles plasmáticos alcanzados dependerán del sexo, edad, peso, cantidad de alcohol ingerido y relación con el tiempo de ayuno transcurrido. Su absorción es rápi$\mathrm{da}$, con un ascenso de la etanolemia en los primeros
15 min y un valor peak a los 30-90 min. La dosis letal en niños descrita es sobre los $4 \mathrm{~g} / \mathrm{kg}$ (etanolemia $>50 \mathrm{mg} / \mathrm{dL})^{3}$.

Su presentación clínica más frecuente es somnolencia, letargo (no necesariamente en relación con los niveles de etanolemia), emesis, dolor y distensión abdominal, siendo la forma más grave de presentación compatible con un toxidrome hipnótico-sedante. En los exámenes de laboratorio iniciales pueden existir alteraciones ácido-base y electrolíticas (hipokalemia) e hipoglicemia. Esta última complicación es inhabitual en la actualidad ${ }^{3}$.

En la atención de urgencia no se recomienda efectuar medidas de descontaminación gastrointestinal (lavado gástrico o carbón activado) debido a su rápida absorción y por riesgo de aspiración pulmonar.

Se debe tener precaución con el eventual desarrollo de hipotermia (frecuente en lactantes), deshidratación por poliuria (inhibición de hormona antidiurética) e hipoglicemia (inhibición gluconeogénesis y disminución del glicógeno hepático). En los casos graves se han descrito arritmias cardíacas e hipotensión arterial (deshidratación y vasodilatación periférica). La magnitud del compromiso de conciencia y la depresión respiratoria puede hacer necesario la intubación endotraqueal ${ }^{4}$.

Su tratamiento es exclusivamente de soporte vital, asegurando un buen aporte parenteral de glucosa y vigilando la aparición de posibles complicaciones. Se deben usar protectores gástricos como omeprazol o ranitidina y antieméticos en caso de vómitos. El uso de hemodiálisis puede ser considerado en los casos de intoxicación grave (elevada etanolemia con acidemia), pero su beneficio sobre terapias de soporte no está definitivamente establecido ${ }^{3}$.

En la actualidad la intoxicación por etanol en preescolares y escolares es poco común ${ }^{4}$, sin embargo, en tiempos de pandemia es importante reforzar la supervisión de los padres a los hijos, pues estos últimos

Correspondencia:

Gianfranco Tomarelli Rubio

gtomarelli@hotmail.com 
se encuentran más expuestos a situaciones de riesgo intradomiciliario; como también es labor del equipo de salud tener un alto nivel de sospecha y enfatizar las recomendaciones de prevención toxicológica para este $\mathrm{u}$ otros potenciales tóxicos al momento de la atención del niño y su familia.

Gianfranco Tomarelli Rubio ${ }^{a}$, Alejandro Donoso Fuentes ${ }^{a}$ ${ }^{a}$ Médico intensivista. Unidad de Paciente Crítico Pediátrico. Hospital Clínico Dra. Eloísa Díaz I. La Florida.

\section{Referencias}

1. Rayar P, Ratnapalan S. Pediatric ingestions of house hold products containing ethanol: A review. Clin Pediatr (Phila). 2013;52(3):203-9.

2. Edmonds SL, Mann J, McCormack RR, et al. Sani Twice: a novel approach to hand hygiene for reducing bacterial contamination on hands when soap and water are unavailable. J Food Prot. 2010;73(12):2296-300.

3. Gaw CE, Osterhoudt KC. Ethanol Intoxication of Young Children. Pediatr Emerg Care. 2019;35(10):722-30.

4. Hon KL, Leung AKC, Cheung E, Lee B, Tsang MMC, Torres AR. An overview of exposure to ethanol-containing substances and ethanol intoxication in children based on three illustrated cases. Drugs in Context 2018; 7: 212512. 